\title{
Peertechz $z^{\circ}$
}

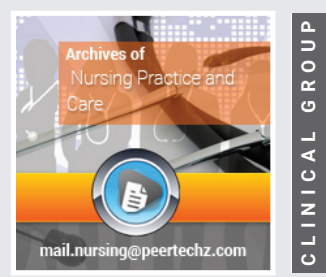

\section{Measures and effect in preventing and controlling COVID-19 in Shenzhen}

Received: 01 June, 2020

Accepted: 16 June, 2020

Published: 17 June, 2020

*Corresponding author: Jing Zheng, Shenzhen Center for Health Information, Shenzhen Guangdong, 518000, China, E-mail: cnzhengj@163.com

https://www. peertechz.com

Check for updates

\section{Shuyan Jin ${ }^{1}$ and Jing Zheng ${ }^{2 *}$ \\ ${ }^{1}$ Shenzhen Maternity and Child Healthcare Hospital, Shenzhen Guangdong, 518000, China \\ ${ }^{2}$ Shenzhen Center for Health Information, Shenzhen Guangdong, 518000, China}

Since December 2019, COVID-19 is still in the global trend of pandemic, prevention and control situation is grim. Shenzhen is adjacent to Hong Kong, with a small area (1997 square kilometers), a large population (23 million people), many ports, immigrant cities and other factors, which have increased the difficulty of preventing and controlling the epidemic situation in Shenzhen. In such a complex situation, Shenzhen handed over a good report card, as of 24 May ,2020, the total number of confirmed cases in Shenzhen is 462, the local infection case is zero in 99 days, until now the confirmed case is zero, the asymptomatic infected case under medical observation is zero [1]. Please see Diagram 1 and Diagram 2 for details. Therefore, the prevention and control measures of COVID-19 in Shenzhen were summarized for reference. The number of patients with COVID 19 in this article is not the number of experimental persons, but the number of cases actually occurred and diagnosed in Shenzhen's 20 million population Figures 1,2.

\section{Measures in controlling COVID-19 in Shenzhen}

Construction of the overall prevention and control system: After the outbreak of SARS in 2003, our city established an influenza prevention and control system, especially for unexplained pneumonia. After many cases of pneumonia emerged in Wuhan at the end of 2019, the prevention and control system was upgraded to establish a barrier for the whole epidemic prevention and control work in Shenzhen. Because of the upgrade of the prevention and control system, Shenzhen discovered the first the first case of COVID in Guangdong Province on January 19, 2020, which was caused by familial aggregation, and proved that children were susceptible population, which saved time for the prevention and control of epidemic diseases in the whole country.

Comprehensive promotion of the family doctor
By the end of 2019, there were 688 social health institutions in Shenzhen, basically realizing "one regional social health center in each street and one social health institution in each community". There were 2,568 family doctor teams in Shenzhen, the total of the signed residents is $4,231,142$, the

As of May 24, 2020 newew diagnosis of COVID-19 in Shenzhen every day

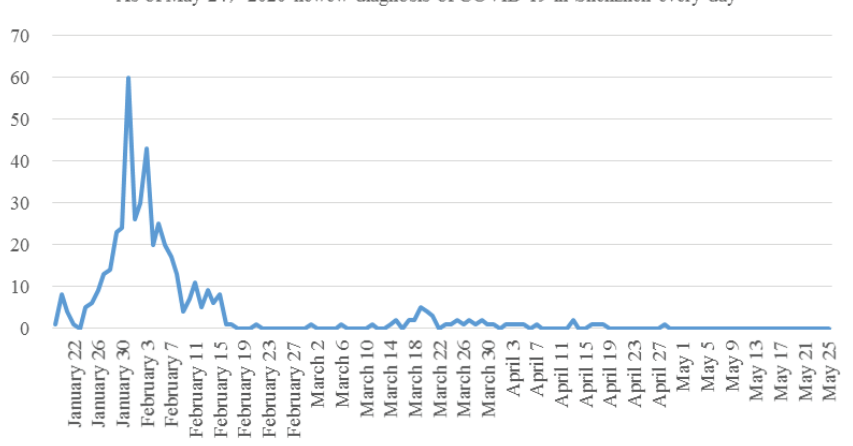

Figure 1: As of 24 May, 2020 new diagnosis of COVID-19 in Shenzhen every day.

As of 24 ay2020, Cumulative confirmed cases of COVID-19 in Shenzhen

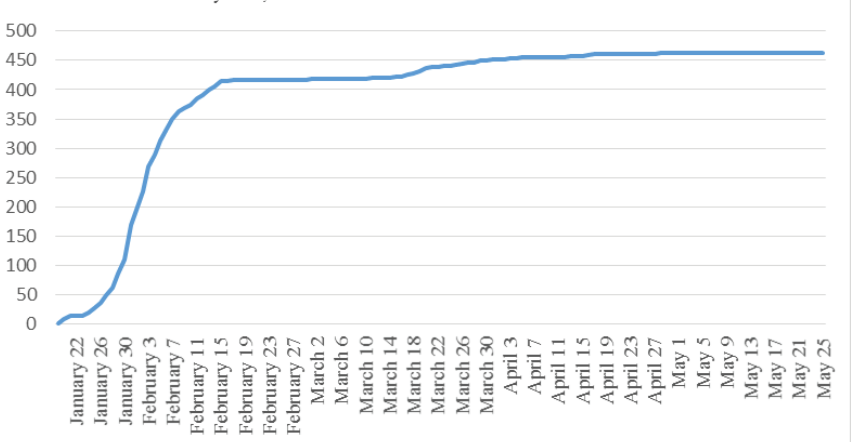

Figure 2: As of 24 May2020, Cumulative confirmed cases of COVID-19 in Shenzhen. 
ratio of signed residents is $34 \%$; while the number of the key signed residents is $1,409,347$, and the ratio of key signed residents reaches to $72 \%$, the group of the family doctors is unceasingly growing up [2]. By establishing the family doctor system, under the family doctor's general practice training mode, through the family doctor to carry out joint prevention and control, health follow-up, fluid disease investigation, health guidance, health education and others, we effectively cut off the transmission of COVID, isolate the source of infection and protect the susceptible population, which play the role of health gatekeeper in the prevention and control of community epidemic diseases in Shenzhen.

\section{Specific epidemic prevention measures}

As of now, the Office of Shenzhen New Coronavirus Pneumonia Prevention and Control Headquarters has issued a number of prevention and control measures to do a good job of COVID 19 prevention and control [3-5]. The main contents include:

Strictly prevent the import of overseas epidemic situations: Strictly follow the guidelines for the prevention and control of overseas imports, and implement all measures. All personnel entering the Shenzhen port, regardless of destination, implement full coverage nucleic acid testing and full isolation at their own expense. Those who meet the conditions of exemption isolation or home isolation shall be implemented in accordance with relevant regulations.

Centralized and isolated treatment: Shenzhen has implemented centralized admission and treatment of designated hospitals for respiratory tract infectious diseases. All suspected patients in the urban area are subject to centralized isolation and treatment. This cuts off the source of infection and slows down the speed of transmission.

Comprehensive inspection: All close contacts are isolated for 14 days, and they can only leave the isolation point after two nucleic acid tests. The isolation cost is borne by the government.

Strengthen the community's precise investigation, prevention and control mechanism: Through the community's "trinity" precise investigation and prevention mechanism, strengthen emergency response to sudden outbreaks, and achieve "early detection, early reporting, early isolation, early treatment" of cases. All pharmacies strictly implement the real-name registration, temperature measurement and reporting system for those who purchase antipyretic and cough medicines. At the same time, all communities in Shenzhen have adopted segregated management measures, including the implementation of closed management in all residential areas, and evaluation of permits to enter and exit the community, and non-community residents cannot enter and exit. At the same time, all citizens bring masks to enter and exit the community to measure body temperature.

Maintain environmental sanitation in various public places, and do a good job of public health protection and publicity and education of COVID 19.

\section{Establishment and application of ACT model}

Community prevention and control in Shenzhen takes community workers, social health medical personnel, community police' trinity' as the core, extending, summing up, refining a set of "ACT" community prevention and control model, and Qiaoxiang village community to achieve "Three Zero ", that is, zero community transmission, zero medical staff infection, zero death cases [6]. A (Administration, that is, the party committee and government are closely organized to allow the source of the virus to "cut off"): community party committee is under the strict organization of the party committee and government, the grassroots party members and cadres participate in the first-line of prevention and control work to cut off the source of the virus; C (Community Health Service Center, that is, the social health center to consolidate its position, set up a fever pre-examination triage table, promptly find fever patients and suspected patients, and do isolation and referral): Community Health Service Center is under the social health center professional support, in preinspection, door-to-door measurement, nucleic acid detection and other works, community residents Health is guaranteed in all directions; $\mathrm{T}$ (Trinity Mechanism, that is, the trinity of community workers, social health medical personnel, and community police, forming a "three-person team" to jointly prevent and control): Trimly Mechanism: The community three-person group, that is, the whole chain of community joint prevention and control system of "party-building and leading + professional protection + multiple participation".

\section{Support of information technology}

Exploring and using big data, Internet and other information technology, from the situation study, resource scheduling, decision support and others to assist the prevention and control work [7]. It mainly includes the analysis of remote consultation, remote health guidance, prognosis, real-time big data report of epidemic diseases, information query of peripheral epidemic situation, non-touch distribution, travel tracing, automatic inquiry and so on, so as to provide fine data support for the prevention and control of diseases.

\section{Effect in preventing and controlling COVID-19 in Shen- zhen}

With the effective development of preventing and controlling measures in Shenzhen, as of 24 May, 2020, the total number of confirmed cases is 462 , the local infection case is zero in 99 days, until now the confirmed case is zero, the asymptomatic infected case under medical observation is zero. Among of the total, 39 cases are imported from overseas, 423 cases are reported on the mainland, and asymptomatic infected case under medical observation in the city keep zero clearing. Of the total confirmed cases, 229 males and 233 females; 3 deaths and cumulative discharge of 459 cases; while 17 close contacts are undergoing medical observation. On February 19, 2020, COVID-19 joint experts' inspection group from China and the World Health Organization went to Shenzhen, after visiting the community of Qiaoxiang Village, they affirmed

Citation: Jin S, Zheng J (2020) Measures and effect in preventing and controlling COVID-19 in Shenzhen. Arch Nurs Pract Care 6(1): 007-009. 
of the community innovative implementation of the "ACT" prevention and control model, and gave the higher appraisal.

All of China has adopted the same strict prevention and control measures. After the outbreak in Wuhan and the rebound of the outbreak in Jilin Province, the closure of the city has effectively cut off the source of infection, blocked the transmission route, and controlled the susceptible people. Under effective control, the number of confirmed cases has declined rapidly.

\section{References}

1. Link: https://bit.ly/30NA6Xs

2. Link: https://bit.ly/2UNdjai
3. Link: https://bit.ly/2UNdq51

4. Notice of the Epidemic Prevention and Control Group of the Office of the Shenzhen New Coronavirus Pneumonia Epidemic Prevention and Control Headquarters on Printing and Distributing the "Shenzhen Human Resources Industry Guidelines for the Prevention and Control of New Coronary Pneumonia Outbreaks and Resumption of Work. Link: https://bit.ly/2V43gOr

5. Notice on Implementing Divisional, Graded Prevention and Control Measures, Scientifically and Orderly Promoting Enterprise Resumption and Production. Link: https://bit.ly/3d6gk23

6. WHO experts like it! Shenzhen this community ACT model. Link: https://bit.ly/3huyoA1

7. Shenzhen Longgang District actively used information technology to assist in the prevention and control of new coronary pneumonia. Link: https://bit.ly/2BgeGqU

\section{Discover a bigger Impact and Visibility of your article publication with}

\section{Peertechz Publications}

\section{Highlights}

* Signatory publisher of ORCID

* Signatory Publisher of DORA (San Francisco Declaration on Research Assessment)

* Articles archived in worlds' renowned service providers such as Portico, CNKI, AGRIS, TDNet, Base (Bielefeld University Library), CrossRef, Scilit, J-Gate etc.

* Journals indexed in ICMJE, SHERPA/ROMEO, Google Scholar etc.

* OAI-PMH (Open Archives Initiative Protocol for Metadata Harvesting)

* Dedicated Editorial Board for every journal

- Accurate and rapid peer-review process

* Increased citations of published articles through promotions

* Reduced timeline for article publication

Submit your articles and experience a new surge in publication services (https://www.peertechz.com/submission).

Peertechz journals wishes everlasting success in your every endeavours

Copyright: @ $2020 \mathrm{Jin}$ S, et al. This is an open-access article distributed under the terms of the Creative Commons Attribution License, which permits unrestricted use, distribution, and reproduction in any medium, provided the original author and source are credited. 